\title{
Clinical features of spontaneous hypothyroidism in one physician's practice in Jamaica
}

This article was published in the following Dove Press journal:

International Journal of General Medicine

18 May 2010

Number of times this article has been viewed

\section{Rosemarie A Wright-Pascoe \\ Department of Medicine, The University of the West Indies, Kingston, Jamaica}

Correspondence: Rosemarie A WrightPascoe

Department of Medicine, The University of the West Indies, Mona, Kingston 7, Jamaica

Tel + I 876927 I707

Fax +| 876977069 |

Email rosemarie.wrightpascoe@uwimona. edu.jm
Objective: To describe the clinical characteristics of patients with spontaneous hypothyroidism, the frequency of chronic autoimmune thyroiditis, and the thyroid autoantibody most often associated with this condition in a referral population in Jamaica.

Methods: A retrospective study of all cases referred to the author's endocrinology practice from 1995 to 2005 with a diagnosis of spontaneous hypothyroidism was undertaken. The clinical history, examination findings, biochemical test results, thyroid autoimmune antibodies, and imaging data were reviewed.

Results: Spontaneous primary hypothyroidism was correctly diagnosed in 53 subjects. Fifty of the patients were females and three were males. Mean age was 43.3 years (range 12-82 years); $24.4 \%$ of the patients had a family member with thyroid disease; $27.1 \%$ presented because of a goiter; and $54.2 \%$ because of symptoms suggestive of hypothyroidism. The thyroid was palpable in $56.3 \%$ and thyroid ultrasound was consistent with Hashimoto's thyroiditis on 64\% of occasions. Only $8 \%$ of the patients had the atrophic variant of hypothyroidism. Antithyroid peroxidase and antithyroglobulin antibody were positive in $75.8 \%$ and $37.5 \%$ of patients, respectively. Chronic autoimmune thyroiditis was confirmed in $78.8 \%$ of cases.

Conclusion: In these cases in Jamaica, spontaneous hypothyroidism was predominantly a female disorder. Chronic autoimmune thyroiditis was the commonest cause, and antithyroid peroxidase antibody was the thyroid antibody most likely to be positive in this population.

Keywords: spontaneous hypothyroidism, Jamaican, thyroid autoantibodies, L-thyroxine, autoimmune thyroiditis, Hashimoto's thyroiditis

\section{Introduction}

Hypothyroidism is an insidious condition associated with significant morbidity. Its symptoms and signs may be nonspecific and subtle which may result in the diagnosis being missed. It may present as subclinical hypothyroidism, as overt hypothyroidism, or as myxoedema. All three presentations may result in cardiovascular abnormalities, including impairment of endothelial function, normal or depressed systolic function, left ventricular diastolic dysfunction at rest, and/or systolic and diastolic dysfunction on effort, and this may lead to poor physical exercise. There may also be increased diastolic blood pressure due to increased systemic vascular resistance and increased central arterial stiffness. In addition, there may be an abnormal lipid profile. Treatment with levo-thyroxine (L-thyroxine) in both subclinical and overt hypothyroidism results in regression of cardiovascular and lipid abnormalities. ${ }^{1}$ Hypothyroidism is thus a disease that should not be ignored.

The prevalence of spontaneous hypothyroidism in iodine-replete communities is in the range of $1 \%-2 \% .^{2}$ Although the prevalence of unsuspected overt hypothyroidism 
is low, community screening for hypothyroidism in healthy adults has revealed evidence of significant thyroid disease. In the Whickham survey, $8 \%$ of women and $3 \%$ of men were found to have subclinical disease. ${ }^{3}$ In the Colorado screening survey, where $9 \%$ of the population had an elevated thyrotropin (TSH), 74\% had TSH values between 5.1 and $10 \mathrm{mU} / \mathrm{L}^{4}$

In iodine-sufficient areas, the causes of hypothyroidism (other than destructive treatment for hyperthyroidism) are either an autoimmune disease (atrophic autoimmune thyroiditis) or goiterous autoimmune thyroiditis (Hashimoto's disease [HD]).

Hashimoto described the histology of the thyroid gland in individuals with goiter and hypothyroidism in $1912 .{ }^{5}$ The association of thyroglobulin antibodies (anti-TG) with HD or chronic lymphocytic thyroiditis was documented in 1956. Since then, other antibodies, such as the microsomal fraction of the thyroid that are actually directed against thyroid peroxidase (anti-TPO), to thyroxine (T4), triiodothyronine (T3) and the TSH receptor, have been described in this disorder. The thyroiditis often progresses to permanent hypothyroidism. In patients with clinically evident disease, circulating levels of anti-TPO are seen in $90 \%$ or more of patients. ${ }^{6}$ Anti-TG is less frequently positive, being present in $20 \%-50 \%$ of patients. HD is one disorder in the spectrum of autoimmune thyroiditis that includes Grave's disease, the etiology of which is a complex interaction between genetic, environmental, and endogenous factors. For instance, the major histocompatibility complex antigens HLA-B8 and HLA-DR5 are closely associated with this disease. However, these antigens are not seen in certain races. ${ }^{7}$

Jamaica has a predominantly black population of Africa ancestry. The country has been iodinating salt for some time now. ${ }^{8}$ There are no studies that have evaluated the commonest causes of spontaneous hypothyroidism in Jamaicans or defined the clinical characteristics of patients with this disorder. It is expected that HD would be the commonest cause of primary hypothyroidism in the Jamaican population. It is unknown which thyroid autoantibody is best for defining the disorder in this community.

We had previously documented the limited usefulness of anti-TPO and anti-TG in the diagnosis of Grave's disease in Jamaicans. ${ }^{9}$ The purpose of this study was to define the clinical characteristics of Jamaican patients with spontaneous hypothyroidism, to evaluate the frequency of chronic autoimmune thyroiditis in these patients, and to determine which antibody was most associated with this disorder in Jamaicans.

\section{Patients and methods}

This was a retrospective study of patients who were referred in 1995-2005 to the author's single-physician practice that offers endocrine consultations. Inclusion criteria included a referral diagnosis of spontaneous hypothyroidism and not secondary to thyroid or neck surgery, radioiodine therapy, or radiation to head or neck. Primary hypothyroidism was diagnosed if there was elevated TSH with normal or decreased free thyroxine (FT4) or free thyroxine index (FT4I), or if there was only elevated TSH. Overt hypothyroidism was defined as a decreased FT4I or FT4 with elevated TSH, and subclinical hypothyroidism as normal FT4I or FT4 with elevated TSH. Spontaneous hypothyroidism was defined as hypothyroidism occurring in the absence of surgery to the neck or thyroid gland, absence of radiation to the neck or the gland, and absence of radioiodine therapy or treatment with amiodarone. Data obtained from patient charts included age, sex, family history of thyroid disease, initial clinical presentation, clinical features of the thyroid gland itself, functional thyroid status defined by thyroid function tests [TFTs], thyroid ultrasonographic features, and thyroid autoantibodies. The thyroid autoantibodies evaluated were anti-TG and anti-TPO. TFTs and titers of the thyroid autoantibodies were expressed as percentages of the norms because the values were obtained from different laboratories with different normal values and ranges. The dosage of L-thyroxine needed to attain euthyroidism was also evaluated. Euthyroidism was defined as normal FT4 or FT4I and normal TSH.

\section{Results}

During the study period, 1278 patients were referred to this practice. Eighty-eight patients had been referred with a diagnosis of presumed spontaneous hypothyroidism. However, 35 were excluded from the study for a range of reasons, including two who had thyrotoxicosis, four who had received radioiodine therapy, five who had had thyroid surgery, 19 who had secondary rather than primary hypothyroidism, two with a history of hypothyroidism not confirmed by TFTs, and three who had normal TFTs after being taken off L-thyroxine. Spontaneous primary hypothyroidism was seen in $4.15 \%$ of the patients in this referral practice (Table 1).

Our study population consisted of 53 patients, including 50 females and three males of mean age 43.3 (range 12-82) years. Family history was known in 45 of these patients, and was positive for goiter, hypothyroidism, or hyperthyroidism in $24.4 \%$ of cases; $72.7 \%$ of the affected family members were firstdegree relatives. The reason for presenting to a family physician for evaluation was known in 48 patients and was because of a 
Table I Thyroid status and exclusion criteria

\begin{tabular}{ll}
\hline & (n) \\
\hline Total number referred & 1278 \\
Total number referred with diagnosis & 88 \\
of primary hypothyroidism & \\
Total number with actual diagnoses: & \\
- thyrotoxicosis & 2 \\
- radioiodine therapy & 4 \\
- thyroid surgery & 5 \\
- secondary hypothyroidism & 19 \\
- euthyroidism & 3 \\
- not confirmed & 3
\end{tabular}

Notes: Prevalence of spontaneous primary hypothyroidism in this endocrine practice was $4.15 \%$.

goiter in $27.1 \%(\mathrm{n}=13)$, and because of experiencing symptoms suggestive of hypothyroidism in 54.2\% $(\mathrm{n}=26)$. Abnormal TFTs were an incidental finding in $16.7 \%$ of patients.

Results of thyroid palpation were known in 48 subjects. The thyroid was palpable in $56.3 \%$ and, of 25 patients who had undergone thyroid ultrasonography, features were consistent with HD in $64 \%$ of cases. Nodularity was seen in $20 \%$, and a smaller than normal gland in $8 \%$ of patients. Chronic atrophic thyroiditis was therefore seen in $8 \%$ of cases. Thyroid ultrasonography was normal in $8 \%$ of patients.

The types of hypothyroidism, and overt versus subclinical hypothyroidism were known in 48 patients. Overt hypothyroidism was noted in $54.8 \%$ of cases. The median FT4I or FT4 was 53.3\% (range 8.62\%-95.73\%) of normal.

Subclinical hypothyroidism was seen in 16 (38.1\%) of the patients. There were three who had only an elevated TSH available for analysis and were not included in the category of subclinical hypothyroidism. The prevalence of subclinical hypothyroidism in this practice was $1.25 \%$. Of the total with elevated TSH, the median value was elevated to $615 \%$ of the norm (range 109.7\%-28236\%).

Anti-TPO was performed in 33 of the patients and anti-TG in 32 . The former was positive on $75.8 \%$ of occasions $(n=25)$ whereas the latter was positive on only $37.5 \%$ of occasions $(n=12)$. Anti-TG was negative on $41.7 \%$ of occasions in those with a positive anti-TPO. Of those with a positive anti-TG, anti-TPO was negative in only one case (8.3\%). The anti-TPO titer was elevated by more than $1000 \%$ of the norm in $80 \%$ of patients $(n=22)$ and the anti-TG titer in six of 12 subjects $(50 \%)$.

The average dose of L-thyroxine needed to attain euthyroidism in this population was known in $50.9 \%$ of the patients $(n=27)$ and in $50 \%(n=8)$ of those with subclinical hypothyroidism. The L-thyroxine dose needed was 1.47 (range $0.88-2.20) \mu \mathrm{g} / \mathrm{kg}$ in the former group and $0.99 \mu \mathrm{g} / \mathrm{kg}$ (range 0.88-1.41) in the latter group (Table 2).

\section{Discussion}

The clinical characteristics of Jamaican patients with spontaneous hypothyroidism referred to an endocrinology practice are described. The patients were more likely to be female than male. Other studies have noted the preponderance of females with this disorder. The disease was predominantly seen in middle-aged patients in our study, as reported by others. $^{3}$ The family history of thyroid disease seen in our patients is also consistent with previous reports. ${ }^{10}$ Tamai et al documented that within a six-month to five-year period, $7.2 \%$ of previously euthyroid relatives of patients with Grave's disease developed hyperthyroidism or hypothyroidism. Tomer et al identified that there are multiple genes that predispose

Table 2 Clinical characteristics of identified patients

\begin{tabular}{|c|c|}
\hline Gender (Female:Male) & $50: 3$ \\
\hline Median age (years) & 43.3 \\
\hline (range in years) & $(12-82)$ \\
\hline Family history of thyroid disease $(n=I I)$ & $24.4 \%$ \\
\hline Causes for presentation $(n=48)$ & $70.0 \%$ \\
\hline Goitre $(n=13)$ & $27.1 \%$ \\
\hline Hypothyroidism ( $n=26)$ & $54.2 \%$ \\
\hline Incidental $(\mathrm{n}=8)$ & $16.7 \%$ \\
\hline Other $(n=1)$ & $2.1 \%$ \\
\hline \multicolumn{2}{|l|}{ Results of thyroid examination $(n=48)$} \\
\hline Palpable $(n=27)$ & $56.3 \%$ \\
\hline Not palpable $(n=21)$ & $43.7 \%$ \\
\hline \multicolumn{2}{|l|}{ Results of thyroid ultrasound $(n=25)$} \\
\hline Hashimoto's thyroiditis $(n=16)$ & $64 \%$ \\
\hline Nodular $(n=5)$ & $20 \%$ \\
\hline Smaller than normal $(n=2)$ & $8.0 \%$ \\
\hline Normal $(n=2)$ & $8.0 \%$ \\
\hline \multicolumn{2}{|l|}{ Types of hypothyroidism $(n=42)$} \\
\hline Overt hypothyroidism $(n=23)$ & $54.8 \%$ \\
\hline Subclinical hypothyroidism $(n=16)$ & $38.1 \%$ \\
\hline Unknown $(n=3)$ & $7.1 \%$ \\
\hline \multicolumn{2}{|l|}{ TSH value } \\
\hline Median value of the TSH (\% of the norm) & 615 \\
\hline \multicolumn{2}{|l|}{ Positive thyroid autoantibodies } \\
\hline Anti-TPO $(n=33)$ & $75.8 \%$ \\
\hline Anti-TG $(n=32)$ & $37.5 \%$ \\
\hline Positive anti-TPO and negative anti-TG & $41.7 \%$ \\
\hline Positive anti-TG and negative anti-TPO & $8.3 \%$ \\
\hline \multicolumn{2}{|l|}{ Average L-thyroxine dose } \\
\hline All patients $(n=27)$ & $1.47 \mu g / \mathrm{kg}$ \\
\hline Range & $0.88-2.20 \mu \mathrm{g} / \mathrm{kg}$ \\
\hline Subclinical hypothyroidism $(\mathrm{n}=8)$ & $0.99 \mu \mathrm{g} / \mathrm{kg}$ \\
\hline Range & $0.88-1.4 \mathrm{I} \mu \mathrm{g} / \mathrm{kg}$ \\
\hline
\end{tabular}

Abbreviations: TSH, thyroid-stimulating hormone; anti-TPO, antibody against thyroperoxidase; anti-TG, antibody against thyroglobulin. 
to Grave's disease and hypothyroidism, and that although some are unique to each disease, many are common to both conditions. ${ }^{11}$ However, the Whickham Survey follow-up study did not document an association between family history of thyroid disease and risk of developing hypothyroidism 20 years later. ${ }^{12}$ This suggests that factors other than genetics are important. In fact, the concordance rate for autoimmune hypothyroidism in monozygotic twins is less than $1 .{ }^{13}$ Environmental factors have also been implicated. In this study we did not evaluate any of these environmental factors, such as high iodine intake, selenium deficiency, pollutants such as tobacco smoke, or infectious diseases such as chronic hepatitis C. ${ }^{14}$

In our study, the diagnosis was suggested by the presence of goiter on only a minority of occasions. The usual presentation is that of goiter being discovered as an incidental finding during clinical examination. ${ }^{15}$ Fifty percent of our patients presented with symptoms of hypothyroidism, although this is an unusual finding. In the series by Doniach et al symptoms of hypothyroidism were seen at presentation in only $20 \%$ of patients. ${ }^{16}$ The thyroid gland usually has a diffuse, very firm, or even hard goiter. Nodules are seen infrequently, unlike the nodular thyroid gland documented in $20 \%$ of our patients. However, in a series by Erdogan et al nodularity on ultrasonography was a common finding. ${ }^{17}$ The presence of a single nodule should be evaluated for thyroid carcinoma. None of our patients had this. The possibility of thyroid lymphoma, especially in the elderly, should always be borne in mind when an elderly patient has hard, firm nodules, if there has been enlargement of the thyroid gland over time, or when there are symptoms of compression.

As expected, the atrophic variant of HD was detected in only a minority of cases. ${ }^{17}$ The reduced echogenicity seen in $64 \%$ of our patients is lower than the $77.9 \%$ seen in the series by Pederson et al. ${ }^{18}$ In that study, they compared the ultrasound findings from multiple ultrasonographers with cytology, anti-TPO titers and/or TSH levels. Of the 452 cases of diffuse reduction in thyroid echogenicity, 352 had Hashimoto's thyroiditis and 47 had Grave's disease, giving reduced echogenicity a positive predictive value for autoimmune thyroiditis of $85 \%-91 \%$ at a $95 \%$ confidence interval. In another study, Vitti et al found an abnormal thyroid ultrasound pattern in $96 \%$ of cases of atrophic variant of hypothyroidism, with these subjects having both an abnormal thyroid echographic pattern and a diffuse low thyroid volume. ${ }^{19}$ Thirty-eight percent of the patients with hypothyroidism had subclinical hypothyroidism and 54.8\% had overt hypothyroidism. In the Colorado study, there were more patients with subclinical than overt hypothyroidism. The difference in our study may be the result of the referral practices of general practitioners, economics, and the health-seeking behavior of patients, rather than reflective of the general population. Variation in prevalence may also reflect the cut-off value for TSH, as well as the age, ethnicity, and gender of the population studied. ${ }^{10}$ For instance, blacks in the US who are free of thyroid diseases are noted to have lower TSH values. ${ }^{20}$

The prevalence of thyroid autoantibodies in the general Jamaican population is $1.5 \%$. It is similar to that seen in other populations. $^{21}$ Thyroid peroxidase antigen, once known as thyroid microsomal antigen, is present on the apical surface of thyroid follicular cells. This is the antigen that appears to be most closely involved in cell-mediated cytotoxicity. ${ }^{22}$ It is suggested that the presence of this antibody is most closely related to the development of hypothyroidism. In fact, in the NHANES III study, anti-TPO (but not anti-TG) was a predictor of hypothyroidism. ${ }^{23}$ The prevalence of anti-TPO in our patients with primary hypothyroidism was $75.8 \%$. This is lower than that reported in patients with hypothyroidism discovered in the study of the general population in the US. Whilst the anti-TPO titer declines with increasing duration of the disease, the difference most likely reflects differences in genetic and environmental influences. ${ }^{7,20}$ Anti-TG was less frequently seen than anti-TPO. This was also the experience in the study by Baker et al who documented that 15 of 65 patients had this antibody. ${ }^{24}$ It suggests that anti-TPO is sufficient alone as a diagnostic test for chronic autoimmune thyroiditis in our population. However, in one of our patients, anti-TPO was negative and anti-TG was positive. So, while anti-TG may not be a good predictor of hypothyroidism, it remains an important marker of this chronic autoimmune disease.

The average dose of L-thyroxine needed to make patients euthyroid in the present study was higher than the $1.06 \pm 0.36 \mu \mathrm{g} / \mathrm{kg}$ per day noted by Checchi et al in an Italian population and by Gordon in an American population. ${ }^{25,26}$ While this higher dose may be related to low patient compliance, drug interference, and malabsorption, Checchi documented that increased dosages were seen where parietal cell antibodies were present. This association were seen where parietal cell antibodies were present even in the absence of gastritis. This observation will require further exploration in the Jamaican population, in which $1.4 \%$ of individuals have antibodies against the parietal cell. ${ }^{21}$

\section{Conclusion}

The patients with spontaneous hypothyroidism were typically female and middle-aged. There were more cases 
of subclinical than overt hypothyroidism, and there were differences in their mode of presentation and in the degree of nodularity of the gland. Thyroid antibody positivity in this population was $78.8 \%$. The most commonly seen antibody was anti-TPO. It is suggested that a population-wide study be performed to evaluate further the clinical features of this disorder in the general population.

\section{Disclosure}

The author reports no conflicts of interest in this work.

\section{References}

1. Duntas LH. Thyroid disease and lipids. Thyroid. 2002;12:287-293.

2. Vanderpump MPJ, Tunbridge WMG. Epidemiology and prevalence of clinical and subclinical hypothyroidism. Thyroid. 2002;12:839-847.

3. Tunbridge WMC, Evered DC, Hall R, et al. The spectrum of thyroid disease in the community. The Whickham Survey. Clin Endocrinol. 1977;7:481-493.

4. Canaris GJ, Manowitz NR, Mayor G, Ridgway EC. The Colorado thyroid disease prevalence study. Arch Int Med. 2000;160:526-534.

5. Hashimoto H. Zur Kenntniss der lymphomatosen veranderung der schilddruse (struma lymphomatos). Arch Klin. 1912;97:219-223. German.

6. Solomon DH, Beall GN, Terasaki PI, et al. Autoimmune thyroid disease Graves' and Hashimoto's. Ann Intern Med. 1978;88:379-391.

7. Farid NR, Bear JC. Autoimmune endocrine disorders and the major histocompatibility complex. In: Davies TF, editor. Autoimmune Endocrine Disease. New York, NY: John Wiley \& Sons; 1983.

8. Pan American Health Organisation, Regional Office of the World Health Organization. Jamaica. Health for All 2000. Available at: http://www. paho.org/english/sha/jamrstp.htm. Accessed on 2009 December 28.

9. Wright-Pascoe R, Smikle MF, Barton EN, James OB. Limited usefulness of antithyroperoxidase and antithyroglobulin assays in Jamaicans with Graves' disease. Hum Antibodies. 1999;9:161-164.

10. Tamai H, Ohsako N, Takeno K, et al. Changes in thyroid function in euthyroid subjects with a family history of Graves' disease: A follow-up study of 69 patients. J Clin Endocrinol Metab. 1980;51:1123-1127.

11. TomerY, Ban Y, Concepcion E, et al. Common and unique susceptibility loci in Graves and Hashimoto diseases: Results of whole-genome screening in a data set of 102 multiplex families. Am J Hum Genet. 2003;73:736-747.
12. Vanderpump MP, Tunbridge WM, French JM, et al. The incidence of thyroid disorders in the community: A twenty-year follow-up of the Whickham Survey. Clin Endocrinol (Oxf). 1995;43:55-68.

13. Brix TH, Kyvik KO, Hegedus L. A population-based study of chronic autoimmune hypothyroidism in Danish twins. J Clin Endocr Metab. 2000;85:536-539.

14. Duntas LH. Environmental factors and autoimmune thyroiditis. Nat Clin Pract Endocrinol Metab. 2008;4:454-460.

15. Singer PA. Thyroiditis. Acute, subacute and chronic. Med Clin North Am. 1991;75:61-77.

16. Doniach B, Bottazzo GF, Russell RLG. Goitrous autoimmune thyroiditis (Hashimoto's disease). Clin Endocrinol Metab. 1979;8:63-80.

17. Erdogan M, Erdem N, Cetinkalp S, et al. Demographic, clinical, ultrasonographic, and cytological features of patients with Hashimoto's thyroiditis: Results of a university hospital of 769 patients in Turkey. Endocrine. 2009 Oct 24. [Epub ahead of print]

18. Pederson OM, Aardal NP, Larssen TB, Varhaug JE, Myking O, Vik-Mo $\mathrm{H}$. The value of ultrasonography in predicting autoimmune thyroid disease. Thyroid. 2000;10:251-259.

19. Vitti P, Lampis M, Piga M, et al. Diagnostic usefulness of thyroid ultrasonography in atrophic thyroiditis. J Clin Ultrasound. 1994;22:375-379.

20. Aoki Y, Belin RM, Clickner R, Jeffries R, Phillips L, Mahaffey KR. Serum TSH and total T4 in the United States population and their association with participant characteristics: National Health and Nutrition Examination Survey (NHANES 1999-2002). Thyroid. 2007; 17:1211-213.

21. Mikle MF, James OB. Seroprevalence of autoantibodies in selected and unselected populations in Jamaica. West Indian Med J. 1994;43:5962.

22. Nielsen CH, Brix TH, Leslie RG, Hegedus L. A role for autoantibodies in enhancement of pro-inflammatory cytokine responses to a self-antigen, thyroid peroxidase. Clin Immunol. 2009;133:218-227.

23. Schmidt M, Voell M, Rahlff I, et al. Long-term follow-up of antithyroid peroxidase antibodies in patients with chronic autoimmune thyroiditis Hashimoto's thyroiditis treated with levothyroxine. Thyroid. 2008; 18:755-760.

24. Baker BA, Gharib H, Markowitz H. Correlation of thyroid antibodies and cytological features in suspected autoimmune thyroid disease. $A m$ J Med. 1983;74:941-944.

25. Gordon MB, Gordon MS. Variations in adequate levothyroxine replacement therapy in patients with different causes of hypothyroidism. Endocr Pract. 1999;5:233-238.

26. Checchi S, Montanaro A, Pasqui L, et al. L-thyroxine requirements in patients with autoimmune hypothyroidism and parietal cell antibodies. J Clin Endocrinol Metab. 2008;93:465-469.
International Journal of General Medicine

\section{Publish your work in this journal}

The International Journal of General Medicine is an international, peer-reviewed open-access journal that focuses on general and internal medicine, pathogenesis, epidemiology, diagnosis, monitoring and treatment protocols. The journal is characterized by the rapid reporting of reviews, original research and clinical studies across all disease areas.

\section{Dovepress}

A key focus is the elucidation of disease processes and management protocols resulting in improved outcomes for the patient. The manuscript management system is completely online and includes a very quick and fair peer-review system. Visit http://www.dovepress.com/ testimonials.php to read real quotes from published authors. 